\title{
National Cancer Advisory Board
}

National Cancer Institute

\section{Source}

National Cancer Institute. National Cancer Advisory Board. NCI Thesaurus. Code C18894.

Advise the Secretary, Department of Health and Human Services and the Director, $\mathrm{NCl}$, with respect to the activities of the Institute including reviewing and recommending for support grants and cooperative agreements, following technical and scientific peer review. 